\title{
A realidade educacional das unidades prisionais da região Missões e noroeste do estado do Rio Grande do Sul: um estudo sobre a existência e a quantidade de pessoas em atividades educacionais e sobre as modalidades de ensino cursadas
}

\author{
The educational reality of the prison units of the Missions and \\ northwestern region of the Rio Grande do Sul state: a study on \\ the existence and quantity of people in educational activities and \\ on cursed teaching modalities
}

Serli Genz Bölter ${ }^{l}$

Marizete Burin ${ }^{2}$

\begin{abstract}
RESUMO:
O presente trabalho tem por objetivo analisar a realidade educacional das unidades prisionais da região Missões e Noroeste do estado do Rio Grande do Sul, buscando averiguar a existência de pessoas privadas de liberdade em atividades educacionais, a quantidade de pessoas privadas de liberdade em atividades educacionais, e as modalidades de ensino cursadas. Para tanto, realizou-se uma pesquisa com abordagem qualitativa, por meio de uma amostragem não-probabilística, com escopo exploratório e descritivo, e com análise de material bibliográfico e documental, especialmente com dados oriundos do Departamento Penitenciário Nacional. Com a presente pesquisa identificou-se que existem pessoas privadas de liberdade em atividades educacionais na região Missões e Noroeste do estado do Rio Grande do Sul, constatou-se a existência de 360 pessoas em atividades educacionais (de um total de 2.341 pessoas privadas de liberdade), e verificou-se que essas pessoas cursam modalidades de ensino de instrução escolar (alfabetização, ensino fundamental e ensino médio).
\end{abstract}

PALAVRAS-CHAVE:

Educação formal - Direito à educação - Realidade prisional.

\begin{abstract}
:
The objective of this study is to analyze the educational reality of prison units in the Missões and Noroeste region of the state of Rio Grande do Sul, seeking to investigate the existence of persons deprived of their liberty in educational activities, the number of persons deprived of

\footnotetext{
${ }^{1}$ Doutorado em Programa de Pós-Graduação em Sociologia pela Universidade Federal do Rio Grande do Sul, Brasil (2013).Professor Adjunto I da Universidade Federal da Fronteira Sul , Brasil.

${ }^{2}$ Mestra em Desenvolvimento e Políticas Públicas pela Universidade Federal da Fronteira Sul (UFFS/RS, 2019). Pós-graduada em Ciências Criminais pela Universidade Estácio de Sá/Complexo de Ensino Renato Saraiva
} (UNESA/RJ, 2018)
\end{abstract}


their liberty in educational activities, and the teaching modalities studied. For that, a research with a qualitative approach was carried out, through a non-probabilistic sampling, with exploratory and descriptive scope, and analysis of bibliographical and documentary material, especially with data from the National Penitentiary Department. The present study identified that there are persons deprived of their freedom in educational activities in the Missões and Noroeste region of the state of Rio Grande do Sul. It was verified that there were 360 people in educational activities (out of a total of 2,341 persons deprived of their liberty), and it was verified that these people attend school instruction programs (literacy, elementary and high school).

\section{KEYWORDS:}

Formal education - Right to education - Prison reality. 


\section{INTRODUÇÃO}

O presente trabalho tem por objetivo analisar a realidade educacional das unidades prisionais da região Missões e Noroeste do estado do Rio Grande do Sul, buscando averiguar a existência de pessoas privadas de liberdade em atividades educacionais, a quantidade de pessoas privadas de liberdade em atividades educacionais, e as modalidades educacionais cursadas.

Assim, realizou-se uma pesquisa com abordagem qualitativa, por meio de uma amostragem não-probabilística, com objetivo exploratório e descritivo, e com análise de material bibliográfico e documental, especialmente de dados oriundos do Departamento Penitenciário Nacional. O presente estudo faz parte de uma pesquisa que está sendo desenvolvida no Programa de Pós-graduação Stricto Sensu em Desenvolvimento e Políticas Públicas na Universidade Federal da Fronteira Sul, Campus Cerro Largo/RS, e é vinculada ao Grupo de Pesquisa Direitos Humanos, Movimentos Sociais e Instituições (GP. DIRSOCIAIS) na Universidade Federal da Fronteira Sul, Campus Cerro Largo/RS.

Primeiramente, busca-se analisar a educação na perspectiva teórica de dois autores brasileiros, de Sérgio Haddad e de Paulo Freire, sob o aspecto da educação como uma forma de exercício da cidadania e como uma prática da liberdade. De uma educação baseada na reflexão da realidade em que o educando está inserido, e de uma educação que conduz a cidadania, a participação e a democracia.

Em sequência, pretende-se analisar o direito à educação nos moldes como ele é previsto no ordenamento jurídico brasileiro. Pontuando questões, sobre esse direito, presentes na Constituição da República Federativa do Brasil de 1988 e na Lei de Execução Penal de 1984.

E, por fim, almeja-se analisar a realidade educacional das unidades prisionais da região Missões e Noroeste do Estado do Rio Grande do Sul, sob três aspectos bem definidos e mencionados acima, a fim de que se possa compreender como é a situação educacional desse recorte regional.

\section{PESPECTIVA TEÓRICA: A EDUCAÇÃO COMO EXERCÍCIO DA CIDADANIA E COMO PRÁTICA DA LIBERDADE}

Revista Juris Poiesis - Rio de Janeiro. Vol.22-n²8, 2019, pg.140- 156. ISSN 2448-0517 
Almeja-se, inicialmente, apresentar e relacionar as perspectivas teóricas de dois autores brasileiros, Paulo Freire e Sérgio Haddad. O primeiro desenvolveu uma teoria sobre educação de jovens e adultos, defendendo a educação como uma prática da liberdade. E o segundo, que é adepto a metodologia proposta pelo primeiro, expôs questões sobre o direito à educação, sustentando a ideia da educação como um exercício da cidadania.

Ambos possuem uma concepção semelhante sobre educação, especialmente porque acreditam que a educação deve acontecer com a reflexão da realidade em que o educando está inserido, e porque acreditam que a educação conduz a cidadania, a participação e a democracia.

Apresenta-se essa perspectiva teórica antes de analisar os dados sobre a educação nas unidades prisionais da região Missões e Noroeste do estado do Rio Grande do Sul, pois acredita-se que o direito à educação não pode ser apresentado sozinho, desvinculado de suas bases conceituais.

Assim, primeiramente serão expostas noções básicas sobre a teoria que Paulo Freire elaborou, e posteriormente serão apresentados os norteamentos feitos por Sérgio Haddad. E, na medida do possível, serão relacionados os pensamentos de ambos os autores.

Paulo Freire elaborou uma teoria sobre educação que "[...] tem como uma de suas bases o diálogo que possibilita a conscientização com o objetivo de formar cidadãos da práxis progressiva, transformadores da ordem social, econômica e política injusta" (FURTER, 2011).

Freire (2011), em sua metodologia proposta sobre educação, enfatiza, sobretudo, aspectos como a liberdade frente à opressão, a conscientização e a criticidade, que, segundo ele, conduziriam a participação dos educandos e a democracia. Para o autor, a educação seria uma prática da liberdade, onde a prática educativa só alcançaria efetividade com a participação livre ${ }^{3}$ e crítica dos educandos (WEFFORT, 2011, p. 09-10).

Uma educação crítica, segundo o autor (FREIRE, 2011) seria aquela que possibilitasse ao cidadão uma discussão de sua problemática, de sua inserção nessa problemática, que o colocasse em diálogo com o outro, que o levasse à busca da verdade

3 Não se deve confundir a liberdade trazida por Paulo Freire em sua obra com a liberdade que os apenados têm cerceada por uma decisão judicial em razão da prática de uma infração penal. $\mathrm{O}$ autor traz em sua obra uma liberdade frente à opressão e alienação, defendendo que é preciso liberta-se das condições de opressão. 
comum, uma educação que estivesse associada a tomada de consciência da realidade vivida pelo educando. Ou seja, o autor (FREIRE, 2011) acreditava em uma educação que fizesse o educando pensar, perguntar e pesquisar. Em uma educação que fizesse o educando se envolver com a realidade, e a partir disso, refletir e questionar.

O autor (FREIRE, 2011) visualizava uma educação que não fosse desvinculada da vida, que não fosse mecânica, que não fosse memorizada, que não pregasse o oferecimento vertical de cartilhas de aprendizado, que não pregasse o ensino da palavra desvinculada da realidade.

A educação, para o autor (FREIRE, 2011), deveria implicar no desenvolvimento de uma consciência crítica do cidadão (FREIRE, 2011). Isso porque, segundo o autor (FREIRE, 2011), a criticidade é o ponto fundamental da mentalidade democrática. Quanto mais crítico um grupo, mais democrático e permeável será. E quanto menos crítico um grupo, de maneira mais ingênua serão tratados os seus problemas e de maneira mais superficial serão discutidos os seus assuntos.

Dessa forma, a teoria de Paulo Freire interessa ao presente trabalho na medida em que demonstra a importância da educação para a formação do ser humano, para a formação crítica do cidadão, formação que levaria a participação dos indivíduos na vida pública e conduziria a democracia.

Nessa lógica, uma educação como prega Paulo Freire faria a diferença na vida dos indivíduos e na sociedade como um todo, haja vista que essa educação com a participação livre (de opressão) e crítica dos educandos, impulsionaria a reflexão, ao diálogo e a participação deles na sociedade, na luta e conquista de direitos individuais e coletivos.

Assim, a noção interpretada por Paulo Freire de educação, conduziria ao exercício da cidadania, à participação dos cidadãos na vida pública, conduziria, portanto, ao exercício e a concretização da democracia no país. Tal qual é o pensamento de Sérgio Haddad.

Sérgio Haddad é um dos adeptos da metodologia proposta por Paulo Freire, inclusive o cita na obra objeto da análise. No mesmo sentido exposto acima, o autor (HADDAD, 2003) defende que a educação conduz ao exercício da cidadania, e que ela deve acontecer com a reflexão da realidade em que o educando está inserido.

Sérgio Haddad (2003) entende que garantir o acesso à educação às pessoas jovens e adultas é respeitar um direito humano, um direito que satisfaz a vocação do ser humano de querer ser mais, de querer se aperfeiçoar, de querer conhecer mais, de mudar as condições de sua própria existência, e de transformar a realidade em que está inserido. 
Defende, Sérgio Haddad (2003), que "a educação escolar é base constitutiva na formação do ser humano, assim como na defesa e promoção de outros direitos econômicos, sociais e culturais". Diz o autor (HADDAD, 2003), que a educação cria melhores condições para as pessoas exercerem a cidadania, na medida em que possibilita, às pessoas que passam por práticas educativas, em especial no sistema escolar, defender e realizar outros direitos.

Ou seja, segundo o autor (HADDAD, 2003), uma pessoa que passa por uma prática educativa em um sistema escolar, terá melhores condições de conhecer e defender seus direitos, defender o seu direito à saúde, defender a proteção do meio ambiente, defender a sua participação política...

Nesse sentido, pode-se pensar no seguinte exemplo, uma pessoa que tem acesso à educação, e conhece os seus direitos, como por exemplo o direito à saúde, terá mais condições de reivindicar o recebimento de um atendimento médico, o recebimento de remédios na farmácia pública, o recebimento de uma vacina contra a gripe, etc.

Além disso, afirma Sérgio Haddad (2003), no mesmo sentido exposto por Paulo Freire, que seria necessária a realização de uma reflexão pelos educandos e educadores da realidade vivenciada por eles, para que então se possa construir uma sociedade plena em direitos.

Nesse sentido, a educação formal abriria caminhos para os sujeitos questionarem e pensarem sobre a realidade em que estão inseridos, e, a partir dai, para lutar e reivindicar direitos, que poderão melhorar a vida desses sujeitos e da sociedade como um todo. Abriria caminhos para o exercício da cidadania, para zelar pelo direito e pelo dever.

Menciona, o autor (HADDAD, 2003), que jovens e adultos com pouca escolaridade são pessoas que tiveram um direito violado em seu passado, pois perderam a oportunidade de estudar, pois não puderam frequentar a escola. Diz, o autor (HADDAD, 2003), que tais pessoas perderam um importante instrumento, uma importante ferramenta, qual seja, o acesso ao saber produzido pela humanidade.

Sérgio Haddad (2003) acredita que “[...]a educação é uma prática social que serve para prover as pessoas de instrumentos para melhor ler, interpretar e atuar na sua realidade, como sempre nos ensinou Paulo Freire”. Os ensinamentos de Sérgio Haddad interessam ao presente trabalho na medida em que demonstram a relevância do direito à educação, em razão de ser um direito humano, de ser a base de formação do ser humano, e uma ferramenta que conduz a cidadania, a proteção e defesa de outros direitos. 
Bem como, demonstram que se existem jovens e adultos nas penitenciárias que precisam estudar, existem, então, pessoas que já tiveram o seu direito à educação violado anteriormente, pela falta de oportunidade para o estudo na idade apropriada, e, não podem, agora, ter esse direito novamente violado.

Dito isso, é preciso saber como esse assunto é tratado na prática. Por isso, busca-se analisar, por meio de dados do Departamento Penitenciário Nacional, a realidade da educação nas unidades prisionais da região Missões e Noroeste do estado do Rio Grande do Sul.

\section{O DIREITO À EDUCAÇÃO PREVISTO NO ORDENAMENTO JURÍDICO BRASILEIRO}

O direito à educação é mencionado nas cartas constitucionais do Brasil desde 1824, quando a forma de governo do Brasil era uma monarquia e quando o Brasil era denominado Império do Brazil (BRASIL, 1824). Atualmente, transcorridas sete cartas constitucionais, e alterada a forma de governo para república, o direito à educação no Brasil é assegurado pela carta constitucional de 1988, chamada de Constituição da República Federativa do Brasil (BRASIL, 1988).

$\mathrm{Na}$ carta constitucional vigente, o direito à educação é previsto como um direito social, lado a lado com o direito à saúde, ao trabalho, a moradia, a segurança, a alimentação, etc. Bem como é previsto como um direito de todos os cidadãos brasileiros, e como um dever do Estado e da família (BRASIL, 1988).

Nesse sentido, merece destaque o artigo 205 da Constituição Federal. Ele elenca a educação como um direito dos cidadãos brasileiros e como um dever do Estado, deixando explícita a obrigação estatal na garantia da educação aos cidadãos (BRASIL, 1988). Veja:

\footnotetext{
Art. 205. A educação, direito de todos e dever do Estado e da família, será promovida e incentivada com a colaboração da sociedade, visando ao pleno desenvolvimento da pessoa, seu preparo para o exercício da cidadania e sua qualificação para o trabalho (BRASIL, 1988).
}

Ademais, o artigo supracitado também informa os três pontos cruciais no alcance da educação, três objetivos na promoção da educação no Brasil, quais sejam: o pleno desenvolvimento do sujeito, sua preparação para o exercício da cidadania e sua qualificação 
para o trabalho (BRASIL, 1988). Conceitos anteriormente trabalhados pelos autores Paulo Freire e Sérgio Haddad, e extremamente importantes na conquista desse direito.

Além disso, a Constituição Federal também determina como o Estado Brasileiro deve implementar o direito à educação. Em termos gerais, prevê que o Estado deverá efetivar o direito à educação garantindo educação básica, obrigatória e gratuita, dos quatro aos dezessete anos de idade, inclusive assegurando a sua oferta a todas as pessoas que não tiveram acesso à educação na idade própria (BRASIL, 1988).

Nesse sentido, a Carta Magna deixa claro que o direito à educação alcançará outras faixas etárias, que o direito à educação será oferecido tanto para as crianças e adolescentes (dos quatro aos dezessete anos de idade), quanto para os jovens e adultos (os quais não tiveram acesso à educação na idade apropriada).

E quando se garante educação a jovens e adultos, fala-se também das pessoas que estão privadas de liberdade em penitenciárias brasileiras, todas com idade igual ou superior a 18 anos, que muitas vezes não começaram ou não terminaram seus estudos, e, pela Constituição Federal têm o direito à educação garantido.

Além disso, o direito à educação também é previsto na Lei de Execução Penal (Lei de $n^{\circ} 7.210$ de 1984) especificamente para a população que está privada de liberdade (BRASIL, 1984). Reforçando, dessa forma, o direito à educação que já é assegurado pela Constituição da República Federativa do Brasil a todos os cidadãos brasileiros.

Dessa forma, o direito à educação está previsto na Lei de Execução Penal como uma assistência ao preso, com o objetivo de prevenir novos crimes e de orientá-lo no retorno à sociedade, na retomada da vida social fora da penitenciária (BRASIL, 1984). Diz, portanto, a legislação:

Art. 10. A assistência ao preso e ao internado é dever do Estado, objetivando prevenir o crime e orientar o retorno à convivência em sociedade.

Parágrafo único. A assistência estende-se ao egresso (BRASIL, 1984).

Art. 11. A assistência será:

I - material;

II - à saúde;

III -jurídica;

IV - educacional;

V - social;

VI - religiosa. (BRASIL, 1984). 
A Lei de Execução Penal, tal qual a Constituição da República Federativa do Brasil, estabelece algumas peculiaridades sobre o ensino, principalmente mencionando como a educação deverá ser implementada nas unidades prisionais brasileiras.

Segundo a Lei de Execução Penal, a educação prisional abrange a instrução escolar e a formação profissional do preso, ou seja, a educação prisional deverá englobar uma educação básica (compreendida pela educação infantil, pelo ensino fundamental e pelo ensino médio ${ }^{4}$ ) e um ensino profissionalizante (direcionado à qualificação do preso ao trabalho) (BRASIL, 1984).

E, de todas essas modalidades previstas pela legislação, a Lei de Execução Penal tornou obrigatório o oferecimento do ensino fundamental (BRASIL, 1984), aquele que se inicia aos seis anos de idade e tem duração de nove anos (BRASIL, 1996). Assim, a lei tornou o oferecimento do ensino fundamental um direito público subjetivo, de acordo com o artigo 208, §2 $2^{\circ}$, da Constituição Federal, ou seja, um direito cujo não oferecimento ou a oferta irregular, importa na responsabilização da autoridade competente (BRASIL, 1988).

Além disso, a Lei de Execução Penal também estabelece a implantação de bibliotecas nas penitenciárias brasileiras, para o uso pelos presos, com livros instrutivos, recreativos e didáticos, como um modo de estimular o aprendizado e a leitura (BRASIL, 1984). Veja o que diz o dispositivo legal:

Art. 21. Em atendimento às condições locais, dotar-se-á cada estabelecimento de uma biblioteca, para uso de todas as categorias de reclusos, provida de livros instrutivos, recreativos e didáticos (BRASIL, 1984).

E, como uma forma de incentivar a educação prisional, o artigo 126, alterado pela Lei 12.433/11, garantiu a pessoa privada de liberdade que cumpre a pena em regime fechado ou semiaberto, a possibilidade de remir (descontar) parte do tempo de execução da pena pelo estudo (BRASIL, 1984).

Assim, a cada 12 horas de frequência escolar - em atividade de ensino fundamental, ensino médio, ensino profissionalizante, ensino superior ou ensino de requalificação

\footnotetext{
4 Art. 21. A educação escolar compõe-se de:

I - educação básica, formada pela educação infantil, ensino fundamental e ensino médio;

II - educação superior (BRASIL, 1996).

Art. 32. O ensino fundamental obrigatório, com duração de 9 (nove) anos, gratuito na escola pública, iniciandose aos 6 (seis) anos de idade, terá por objetivo a formação básica do cidadão, mediante: (Redação dada pela Lei

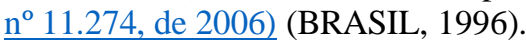


profissional-, divididas em pelo menos 3 dias, poderá descontar 1 dia de pena do condenado (BRASIL, 1984).

Porém, apresar de toda essa previsão legal, é necessário verificar como é a realidade das penitenciárias brasileiras. Para tanto, fazendo um recorte da região Missões e Noroeste do estado do Rio Grande do Sul, no Brasil, busca-se averiguar se existem presos estudando, quantos presos estão estudando, e quais modalidades de ensino eles estão cursando.

\section{A REALIDADE DA EDUCAÇÃO NAS UNIDADES PRISIONAIS DA REGIÃO MISSÕES E NOROESTE DO ESTADO DO RIO GRANDE DO SUL}

O Estado do Rio Grande do Sul é localizado ao sul do Brasil. Faz divisa, ao nordeste, com o estado de Santa Catarina, ao noroeste, faz divisa com a Argentina, ao sudoeste, faz divisa com o Uruguai, e, ao sudeste, faz divisa com o oceano atlântico (GOOGLE MAPS, 2018).

É dividido em 497 municípios (GOVERNO DO ESTADO DO RIO GRANDE DO SUL, 2018), e é segmentado ficticiamente, pela Superintendência dos Serviços Penitenciários do Estado, em nove regiões: Vale dos Sinos e Litoral; Região Central; Missões e Noroeste; Alto Uruguai; Sul; Campanha; Serra; Vale do Rio Pardo e Carbonífera (SUSEPE, 2018).

Das nove regiões que integram o estado do Rio Grande do Sul, pretende-se analisar apenas uma, a região Missões e Noroeste, localizada, como o próprio nome diz, ao noroeste do estado, fazendo divisa com a Argentina (GOOGLE MAPS, 2018). Região que compreende a Universidade Federal da Fronteira Sul, Campus Cerro Largo/RS, onde está sendo desenvolvida a presente pesquisa.

A região Missões e Noroeste têm uma população carcerária de 2.341 pessoas, sendo 2.176 homens e apenas 165 mulheres (DEPEN, 2016). E é composta pelas seguintes penitenciárias: o Instituto Penal de Ijuí, o Instituto Penal de Santo Ângelo, a Penitenciária Modulada de Ijuí, o Presídio Estadual de Cerro Largo, o Presídio Estadual de Cruz Alta, o Presídio Estadual de São Luiz Gonzaga, o Presídio Estadual de Santa Rosa, o Presídio Estadual de Santo Cristo, o Presídio Estadual de Três Passos e o Presídio Regional de Santo Ângelo (SUSEPE, 2018).

As penitenciárias possuem número populacional diversificado. O Instituto Penal de Ijuí tem uma população de 143 pessoas. O Instituo Penal de Santo Ângelo tem uma população de 84 pessoas. A Penitenciária Modulada de Ijuí tem uma população de 589 pessoas, o 
Presídio Estadual de Cerro Largo tem uma população de 68 pessoas, o Presídio Estadual de Cruz Alta tem uma população de 253 pessoas, o Presídio Estadual de São Luiz Gonzaga tem uma população de 172 pessoas, o Presídio Estadual de Santa Rosa tem uma população de 434 pessoas, o Presídio Estadual de Santo Cristo tem uma população de 100 pessoas, o Presídio Estadual de Três Passos tem uma população de 259 pessoas e o Presídio Regional de Santo Ângelo tem uma população de 239 pessoas (DEPEN, 2016).

De um modo geral, essas penitenciárias abrangem as modalidades de regime fechado, de regime semiaberto e de regime aberto ${ }^{5}$. Todavia o Instituto Penal de Ijuí e o Instituto Penal de Santo Ângelo não contemplam a modalidade de regime fechado (DEPEN, 2016), somente regime aberto e semiaberto, possibilitando aos presos que lá estão, estudarem fora da unidade prisional.

Assim, pretende-se analisar, por meio de dados documentais datados de 2016, oriundos do Departamento Penitenciário Nacional, a realidade educacional das unidades prisionais da região Missões e Noroeste, buscando examinar se existem pessoas privadas de liberdade estudando, quantas pessoas privadas de liberdade estão estudando, e quais modalidades de ensino estão cursando.

Porém, antes de iniciar a análise, almeja-se apresentar o grau de instrução da população carcerária da região. A região Missões e Noroeste, tal qual o estado do Rio Grande do Sul, é caracterizada por possuir uma população carcerária majoritariamente formada por pessoas privadas de liberdade com ensino fundamental incompleto, ou seja, aquele que se inicia aos seis anos de idade e tem duração de nove anos (BRASIL, 1996).

Aproximadamente $64,49 \%$ dos homens privados de liberdade da região Missões e Noroeste possui ensino fundamental incompleto, e cerca de 50,96\% das mulheres privadas de liberdade da região Missões e Noroeste possuem ensino fundamental incompleto (SUSEPE, 2018).

É possível também apresentar, de modo mais completo, dados sobre o grau de instrução da população masculina e feminina. Concernente aos homens, cerca de $3,1 \%$ são alfabetizados, 2,2\% são analfabetos, $64,4 \%$ têm ensino fundamental incompleto, $12 \%$ tem ensino fundamental completo, $11,7 \%$ têm ensino médico incompleto, 4,84\% têm ensino médio completo, $0,8 \%$ têm ensino superior incompleto, $0,5 \%$ têm ensino superior completo, e 0,04\% não informaram (SUSEPE, 2018).

5 A Penitenciaria Regional de Santo Ângelo não possui modalidade de regime aberto (DEPEN, 2016). Revista Juris Poiesis - Rio de Janeiro. Vol.22-n²8, 2019, pg.140-156. ISSN 2448-0517 
Com relação as mulheres, 3,2\% são alfabetizadas, 3,2\% são analfabetas, 50,9\% têm ensino fundamental incompleto, $11,6 \%$ têm ensino fundamental completo, $18,7 \% \%$ têm ensino médio incompleto, $8,3 \%$ têm ensino médio completo, 2,5\% têm ensino superior incompleto, e 1,2\% têm ensino superior completo (SUSEPE, 2018).

Assim, de um modo geral, é possível notar a carência educacional da população carcerária da região Missões e Noroeste, a qual, majoritariamente, ainda não terminou o ensino fundamental. E, diante desses dados, é possível atestar a necessidade educacional dessa população, que necessita dar continuidade os seus estudos, e que tem esse direito garantido por lei.

Nesse sentido, é preciso saber como é a realidade educacional nas unidades prisionais da região Missões e Noroeste, buscando averiguar se existem pessoas privadas de liberdade em atividades educacionais, quantas pessoas privadas de liberdade estão em atividades educacionais, e quais modalidades de ensino estão cursando.

Com a análise dos dados, primeiramente, foi possível verificar a existência de pessoas privadas de liberdade em atividades educacionais na região Missões e Noroeste. Das dez penitenciárias que integram a região, em sete penitenciárias existem pessoas em atividades educacionais. No Instituto Penal de Ijuí ${ }^{6}$, no Instituo Penal de Santo Ângelo, na Penitenciária Modulada de Ijuí, no Presídio Estadual de Cruz Alta, no Presídio Estadual de Santa Rosa, no Presídio Estadual de São Luiz Gonzaga, no Presídio Regional de Santo Ângelo (DEPEN, 2016).

Ao mesmo tempo, foi possível examinar que em três unidades prisionais da região Missões e Noroeste, o direito à educação não é devidamente ofertado pelo Poder Público. São elas: o Presídio Estadual de Cerro Largo, o Presídio Estadual de Santo Cristo e o Presídio Estadual de Três Passos. O que é constatado a partir da análise conjunta de três pontos: a inexistência de pessoas privadas de liberdade em atividades educacionais nas penitenciárias, a ausência de professores disponíveis nas penitenciárias e a inexistência ${ }^{7}$ de salas de aula disponíveis nos estabelecimentos prisionais (DEPEN, 2016).

$6 \quad$ No entanto, é preciso esclarecer que, apesar de existirem pessoas privadas de liberdade em atividades educacionais no Instituto Penal de Ijuí e no Instituto Penal de Santo Ângelo, elas estudam foram das unidades prisionais, o que é possibilitado pelo regime aberto e semiaberto. Assim, nessas duas unidades prisionais não existe oferta de educação escolar, o que é possível de ser constado a partir da inexistência de salas de aulas e da inexistência de professores nas referidas unidades prisionais (DEPEN, 2016).

7 É necessário esclarecer que a penitenciária de Três Passos até possui uma única sala de aula com capacidade para 20 pessoas, mas, como mencionado, não possui os outros aspectos (DEPEN, 2016). 
Assim, apesar da Constituição Federal garantir, no artigo 250, que a educação é um direito de todos e um dever do Estado, e apesar da Lei de Execução Penal garantir, no artigo 11, a assistência a educação aos presos, esse direito não é atendido pelo Poder Público. Esse direito não é alcançado à integralidade da população que compõe as penitenciárias da região Missões e Noroeste do Estado do Rio Grande do Sul.

A informação exposta representa uma violação de direitos, uma negação de um direito constitucionalmente previsto à população brasileira, que é base para o desenvolvimento do indivíduo, para o exercício da cidadania e para a qualificação para o trabalho, tal qual prevê a Constituição Federal (BRASIL, 1988). Os dados acima certificam a violação de um direito essencial, como afirma Sérgio Haddad (2003), de um direito humano, um direito que é base da formação do ser humano, de um instrumento importante para a defesa e realização de outros direitos, para a promoção da cidadania.

Em um segundo momento, foi possível verificar a quantidade de pessoas privadas de liberdade em atividades educacionais na região Missões e Noroeste. Ao todo, existem 360 pessoas privadas de liberdade que estão estudando, de um total de 2.341 pessoas que estão presas (DEPEN, 2016). Existindo um número muito reduzido de pessoas em atividades educacionais.

No Instituo Penal de Ijuí existem 3 pessoas em atividades educacionais, no Instituto Penal de Santo Ângelo existe 1 pessoa, na Penitenciária Modulada de Ijuí existem 69 pessoas, no Presídio Estadual de Cruz Alta existem 14 pessoas, no Presídio de São Luiz Gonzaga existem 50 pessoas, no Presídio Estadual de Santa Rosa existem 121 pessoas, no Presídio Regional de Santo Ângelo existem 102 pessoas (DEPEN, 2016).

Desse modo, somente $15,37 \%$ da população prisional desta região está envolvida em atividades educacionais. De 1.176 homens privados de liberdade, apenas 292 estão em atividades educacionais. E de 165 mulheres privadas de liberdade, somente 68 estão em atividades educacionais (DEPEN, 2016).

Todavia, nesse momento, diante da análise que está sendo desenvolvida, não é possível a afirmar o motivo pelo qual poucas pessoas estão estudando, entre as hipóteses pode-se citar: a falta de oferta pelo Poder Público, a falta de incentivo e a falta de interesse dos apenados.

O que se pode afirmar é que há uma população nessa região com pouca instrução, que é caracterizada majoritariamente por não concluir o ensino fundamental, e que, de acordo com os dados, não está dando continuidade aos estudos, não está dando sequência a formação 
escolar (DEPEN, 2016). Essas pessoas com baixo grau de escolarização já tiverem o direito à educação violado quando não estudaram na idade apropriada (HADDAD, 2003).

Há uma população que está deixando de investir na sua formação, que está deixando de investir em ferramentas que auxiliam na promoção e defesa de direitos, em ferramentas que auxiliam os sujeitos a exercerem a cidadania (HADDAD, 2003). Há uma população que está perdendo a oportunidade de refletir sobre a realidade vivenciada, que está perdendo a oportunidade de dialogar e de investir em ferramentas para a formação crítica, para participar da vida pública (FREIRE, 2011).

E, por fim, foi possível verificar que as pessoas privadas de liberdade em atividades educacionais na região Missões e Noroeste cursam apenas as modalidades de ensino de instrução escolar, ou seja, cursam alfabetização, ensino fundamental e ensino médio. Não existindo pessoas cursando alguma modalidade de formação profissional (DEPEN, 2016).

No Instituto Penal de Ijuí há presos cursando o ensino fundamental. No Instituo Penal de Santo Ângelo há preso cursando o ensino médio. Na Penitenciária Modulada de Ijuí há presos cursando o ensino fundamental e o ensino médio. No Presídio Estadual de Cruz Alta há presos cursando a alfabetização e o ensino fundamental. No Presídio Estadual de São Luiz Gonzaga há presos cursando a alfabetização, o ensino fundamental e o ensino médio. No Presídio Estadual de Santa Rosa há presos cursando o ensino fundamental e o ensino médio. E no Presídio Regional de Santo Ângelo há presos cursando a alfabetização, o ensino fundamental e o ensino médio (DEPEN, 2016).

Todavia, como mencionado anteriormente, em nenhuma das unidades prisionais da região das Missões e do Noroeste do estado do Rio Grande do Sul existem pessoas privadas de liberdade cursando ensino superior, cursos técnicos, cursos de formação inicial ou continuada (DEPEN, 2016).

Apesar da Lei de Execução Penal prever que a educação prisional deverá abranger a instrução escolar e a formação profissional (BRASIL, 1984), a realidade das penitenciárias é outra, de modo que a maioria das unidades prisionais não têm pessoas privadas de liberdade cursando as três modalidades de instrução escolar e em nenhuma penitenciária há pessoas cursando alguma modalidade de formação profissional (DEPEN, 2016).

Mais uma vez, diante da análise que está sendo desenvolvida, não é possível afirmar o motivo pelo qual em algumas penitenciárias não existem pessoas cursando as três modalidades de instrução escolar, e o motivo pelo qual não existem em todas as penitenciárias pessoas cursando modalidades de formação profissional. 
É preciso ter em mente que o preso, apesar de ter cometido uma infração penal, está na penitenciária cumprindo a sua pena, que é a privação de sua liberdade. Assim, todos os demais direitos assegurados em lei a eles, inclusive o direito à educação, devem ser assegurados (ONOFRE; JULIÃO, 2013).

Dessa forma, o direito à educação deve ser assegurado em sua plenitude à população apenada, tal qual a Lei de Execução Penal determina, em todas as suas modalidades de ensino, tanto para uma formação básica dos sujeitos que estão encarcerados, quanto para uma formação profissional.

Negar para a população apenada o direito à educação é negar a possibilidade deles se reintegrarem à sociedade, à vida social. E, quando se fala do direito à educação, já não se precisa discutir se ele é necessário ou não, pois parece óbvio que a educação é necessária (GADOTTI, 2010). Isto é:

Quando falamos de educação, já não discutimos se ela é ou não necessária. Parece óbvio, para todos, que ela é necessária para a conquista da liberdade de cada um e o seu exercício da cidadania, para o trabalho, para tornar as pessoas mais autônomas e mais felizes. A educação é necessária para a sobrevivência do ser humano. Para que ele não precise inventar tudo de novo, necessita apropriar-se da cultura, do que a humanidade já produziu. Se isso era importante no passado, hoje é ainda mais decisivo, numa sociedade baseada no conhecimento (GADOTTI, 2010, p.41).

Assim, de um modo geral, foi possível analisar a realidade educacional das unidades prisionais da região Missões e Noroeste do estado do Rio Grande do Sul, que é apenas uma das nove regiões do Estado. Bem como foi possível compreender, um pouco, sobre a situação educacional desse recorte regional.

\section{CONSIDERAÇÕES FINAIS}

Objetivou-se, nesse trabalho, analisar a realidade educacional das unidades prisionais da região Missões e Noroeste do estado do Rio Grande do Sul, buscando averiguar a existência de pessoas privadas de liberdade em atividades educacionais, a quantidade de pessoas privadas de liberdade em atividades educacionais, e as modalidades de ensino cursadas.

Realizou-se, primeiramente, a análise da perspectiva teórica de Sérgio Haddad e Paulo Freire, pois acredita-se que o direito à educação não deve ser apresentado sozinho, 
desvinculado de suas bases conceituais. Posteriormente, passou-se a análise da legislação brasileira. E, por fim, passou-se à análise dos dados.

Com essa pesquisa, identificou-se que na região Missões e Noroeste existem pessoas privadas de liberdade em atividades educacionais. Das dez penitenciárias que integram a região Missões e Noroeste, em sete ${ }^{8}$ penitenciárias existem pessoas em atividades educacionais. Pode-se perceber também que em três unidades prisionais o direito à educação não é devidamente ofertado pelo Poder Público, em afronta direta ao direito constitucionalmente estabelecido (DEPEN, 2016).

Além disso, constatou-se que de 2.341 pessoas privadas de liberdade, apenas 360 pessoas estão em atividades educacionais na região Missões e Noroeste. Ou seja, somente 15,37\% da população prisional da região das Missões e Noroeste está estudando (DEPEN, 2016), o que representa um número reduzido diante da característica dessa população, que é marcada por possuir, de forma majoritária, ensino fundamental incompleto (SUSEPE, 2018).

Ademais, verificou-se que as pessoas privadas de liberdade em atividades educacionais na região Missões e Noroeste cursam apenas as modalidades de ensino de instrução escolar, ou seja, cursam alfabetização, ensino fundamental e ensino médio. Não existindo pessoas cursando alguma modalidade de formação profissional.

Acredita-se que pesquisas como esta oportunizam o diálogo sobre esses assuntos, que muitas vezes são esquecidos pela sociedade, sendo um modo de tornar mais visível a situação vivenciada nas unidades prisionais, fortalecendo o debate sobre alternativas e soluções para os problemas dessa população, que, de um modo geral, refletem na sociedade como um todo.

\section{REFERÊNCIAS BIBLIOGRÁFICAS}

BRASIL. Constituição Federal. Disponível em: http://www.planalto.gov.br/ccivil_03/constituicao/constituicaocompilado.htm. Acesso em: 10 set. 2018.

. Constituição Política do Império do Brasil. Disponível em: http://www.planalto.gov.br/ccivil_03/constituicao/constituicao24.htm. Acesso em: 10 set. 2018.

8 Em duas destas unidades prisionais existem pessoas em atividades educacionais fora das unidades prisionais (que é o caso do Instituo Penal de Ijuí e o Instituo Penal de Santo Ângelo) (DEPEN, 2016). 
Lei de Diretrizes e Bases da Educação Nacional. Disponível em: http://www.planalto.gov.br/ccivil_03/leis/L9394.htm. Acesso em: 12 set. 2018.

Lei de Execução Penal. Disponível em:

$\overline{\mathrm{http}: / /}$ www.planalto.gov.br/ccivil_03/leis/17210compilado.htm. Acesso em: 12 set. 2018.

DEPEN. Departamento Penitenciário Nacional. Disponível em: http://dados.mj.gov.br/dataset/infopen-levantamento-nacional-de-informacoes-penitenciarias. Acesso em: 16 set. 2018.

FREIRE, Paulo. Educação como prática da liberdade. In: . Educação como prática da Liberdade. 14 ${ }^{\mathrm{a}}$ ed. Rio de Janeiro: Paz e Terra, 2011.

FURTER, Pierre. Capa. In: FREIRE, Paulo. Educação como prática da Liberdade. $14^{\mathrm{a}}$ ed. Rio de Janeiro: Paz e Terra, 2011.

GADOTTI, Moacir. A educação como direito. Em YAMAMOTO, A, et al. Cereja discute: educação em prisões. São Paulo: AlfaSol: Cereja, 2010.

GOOGLE MAPS. Rio Grande do Sul. Disponível em: https://tinyurl.com/ycnoprm6. Acesso em: 20 set. 2018.

GOVERNO DO ESTADO DO RIO GRANDE DO SUL. Geografia. Disponível em: https://estado.rs.gov.br/geografia. Acesso em: 02 out.2018.

HADDAD, Sérgio. Educação de Jovens e Adultos, a promoção da Cidadania Ativa e o desenvolvimento de uma consciência e uma cultura de paz e direitos humanos. Disponível em: https://tinyurl.com/y9d6b9z9. Acesso em: 02 set. 2018.

ONOFRE, E. M. C.; JULIÃO, E. F (2013). Educação na Prisão como Política Pública: desafios e tarefas. Educação \& Realidade. Porto Alegre, v. 38, n. 1, p. 51-69, jan./mar. 2013.

SUSEPE. Superintendência dos Serviços Penitenciários. Disponível em: http://www.susepe.rs.gov.br/capa.php. Acesso em: 10 set.2018.

WEFFORT, Francisco C. Educação e Política: Reflexões Sociológicas sobre uma pedagogia da liberdade. In: FREIRE, Paulo. Educação como prática da Liberdade. $14^{a}$ ed. Rio de Janeiro: Paz e Terra, 2011.

Submetido em: 30/11/2018

Aceiro em: 27/03/2019 